\title{
Prevalence of intestinal parasites in Afghan community on the example of patients treated in Ghazni Provincial Hospital
}

\author{
Krzysztof Korzeniewski ${ }^{1}$, Alina Augustynowicz ${ }^{1}$, Anna Lass $^{2}$ \\ ${ }^{1}$ Department of Epidemiology and Tropical Medicine in Gdynia, Military Institute of Medicine, Warsaw, Poland \\ ${ }^{2}$ Department of Tropical Parasitology in Gdynia, Medical University of Gdansk, Poland
}

\begin{abstract}
Background: This study concerns parasitological investigations estimating the prevalence of intestinal parasites in the Afghan community based on the example of patients, both children and adults, treated in the Ghazni Provincial Hospital, in the eastern part of the country.

Materials and methods: In total, 201 admitted patients with internal health problems were examined in the Afghan hospital in March 2012, including 164 children (1-17 years old) and 37 adults aged 18-80. Stool samples were tested in the Department of Epidemiology and Tropical Medicine at the Military Institute of Medicine in Gdynia, Poland using 3 parasitological methods: direct smear, decantation, flotation (light microscopy). Results: Intestinal parasitic infections caused mainly by Ascaris lumbricoides, Giardia intestinalis and Hymenolepis nana were confirmed in 81/164 (49.4\%) children examined. Among adults, 9/37 (24.3\%) patients were infected with intestinal parasites including Ascaris lumbricoides and Giardia intestinalis. Conclusions: The Afghan community, living in poor sanitary conditions with limited access to health services, is one of the most infected populations in the world. The parasitological investigation focused on intestinal parasites performed by the Polish health service among the eastern Afghan inhabitants is still one of the few screening studies in this country.
\end{abstract}

(Int Marit Health 2014; 65, 2: 68-72)

Key words: Afghanistan, intestinal parasites, light microscopy

\section{INTRODUCTION}

Intestinal parasitic infections are one of the biggest health problems in the world [1]. Over 2 milliard people are infected with at least 1 pathogenic intestinal parasite, and 5 milliard live in regions of permanent risk of infection with digestive tract parasites. The risk of transmission is high, especially in Third World countries, where low standards of hygiene, poor sanitary habits and lack of health care favour the spread of orally transmitted diseases [2-4]. The spectrum of clinical manifestations in parasitic infections is wide. It includes asymptomatic carriage, long-lasting diarrhoea, stomach ache and malnutrition leading to severe anaemia. The diagnostics of intestinal parasitic infections is based on light microscopy, which allows for the detection of different stages of intestinal parasites (cyst, oocyst, trophozoite, larva, egg) [5]. Successful detection of parasites with light microscopy is strongly associated with the diagnostic methods used and microscopist's expertise and training. The success rate will rarely be lower than $30 \%$ unless the direct smear method is used by personnel who is inexperienced in parasitological diagnostics. Parasitological laboratories usually use concentration methods, which significantly increases the detection limit of intestinal parasites [6]. Using several diagnostic methods is reasonable for screening studies of both population, characterised by a low infection rate (detection of single pathogens), and communities where infections occur often (detection of all pathogens in multiple infections). The Afghan community, living in poor 
socioeconomic conditions with limited access to the health service, is an example of a high infections rate population. Since 2002, soldiers of the Polish Armed Forces have been stationed in eastern Afghanistan. Under the framework of humanitarian aid, the Polish health service is mandatorily assigned to a Forward Operating Base in Ghazni, where it carries out parasitological research on local populations to detect and eliminate intestinal parasitic infections. The aim of the study was to estimate the prevalence of intestinal parasites in the Afghan community based on the example of children and adults treated in the Provincial Hospital in Ghazni, capital city of the Ghazni province, located in the eastern part of the country.

\section{MATERIALS AND METHODS}

\section{STUDY POPULATION}

In total, there were 201 patients admitted to the Ghazni Provincial Hospital in March 2012 with internal health problems examined in this study. The group consisted of 164 children aged 1-17 and 37 adults aged 18-80. Three stool samples were collected from each patient every 2-3 days, and fixed with $10 \%$ formalin ( 2 tubes) and SAF (sodium acetate-acetic acid-formalin) preservative (1 tube), and transported from eastern Afghanistan to Poland by air transport. The material was stored and investigated in the Department of Epidemiology and Tropical Medicine at the Military Institute of Medicine in Gdynia, Poland. Collected stool samples were examined using 3 parasitological methods using light microscopy: direct smear and decantation, both counterstained with Lugol's solution and flotation acc. Fülleborn. Each of the 3 faeces samples taken from every patient was investigated with the 3 given methods. Therefore, 1809 parasitological investigations were performed in total.

\section{STATISTICS ANALYSIS}

The statistical analysis was performed using the statistical suite StatSoft. Inc. (2011) STATISTICA (data analysis software system), version 10.0. www.statsoft.com and Excel.

The quantitative variables were characterised by the arithmetic mean of standard deviation or median or max/ /min (range). The qualitative variables were presented with the use of count and percentage. In order to check if a quantitative variable derives from a population of normal distribution the W Shapiro-Wilk test was used. The statistical significance of differences between two groups (unpaired variables model) was processed with the t-Student test (or Welch test in the case of lack of homogeneity) or U Mann-Withney test (in cases where conditions of performing the t-Student test were not satisfied or for variables measured by ordinal scale). Chi-squared tests for independence were used for qualitative variables (with the use of Yates correction for cell counts below 10, with check of Cochrane's conditions or with Fisher's exact test). In all the calculations, the statistical significance level of $p=0.05$ was used.

\section{RESULTS}

In order to estimate the prevalence of intestinal parasites laboratory studies were performed in 164 children with a mean age of 6.9 years (67.7\% males), as well as in 37 adults with a mean age of 39.1 years (75.7\% females). Infected children were statistically significantly older than non-infected ( $p=0.0001)$. There was not a statistically significant age difference depending on infection in the adult group ( $p=0.2072$ ) (Table 1$)$.

Intestinal parasite infections were found in 81 children (49.4\% of population studied). Mixed invasion (with at least 2 parasites) was observed in 37 children. Nematodes (Ascaris lumbricoides), protozoa (Giardia intestinalis) and cestodes (Hymenolepis nana) were the most commonly detected parasites (Table 2).

Nine/37 adults (24.3\% of the population studied) were infected with intestinal parasites; mainly nematodes (Ascaris lumbricoides) and protozoa (Giardia intestinalis). Three patients were infected with more than one intestinal parasite (Table 3).

\section{DISCUSSION}

Afghanistan, according to the United Nations classification of 182 countries regarding their wealth and economic development level, takes penultimate place on the list being, for years, one of the poorest countries in the world. The country is second in the world for childbirth related death

Table 1. Distribution of age and sex of Afghan patients $(n=201)$

\begin{tabular}{|c|c|c|c|c|c|c|c|}
\hline & $\mathbf{N}$ & Per cent male & Mean age & Standard deviation & Median age & Age range & $\mathbf{P}$ \\
\hline Children & 164 & 67.7 & 6.9 & 4.6 & 7.0 & $1-17$ & 0.0001 \\
\hline Infected & 81 & 75.3 & 8.8 & 3.8 & 9.0 & $1-16$ & \\
\hline Non-infected & 83 & 60.2 & 5.1 & 4.7 & 3.0 & $1-17$ & \\
\hline Adults & 37 & 24.3 & 39.1 & 16.5 & 40.0 & $18-80$ & 0.2072 \\
\hline Infected & 9 & 44.4 & 33.0 & 15.4 & 30.0 & $18-60$ & \\
\hline Non-infected & 28 & 17.9 & 41.0 & 16.6 & 41.0 & $18-80$ & \\
\hline
\end{tabular}


Table 2. Parasitic infections in Afghan children

\begin{tabular}{|c|c|c|c|c|}
\hline \multicolumn{2}{|c|}{ Parasite infections } & \multirow{2}{*}{$\begin{array}{l}\begin{array}{l}\text { Number of } \\
\text { infections }\end{array} \\
40\end{array}$} & \multirow{2}{*}{$\begin{array}{l}\begin{array}{l}\text { Percentage of } \\
\text { infections }(\mathbf{n}=\mathbf{8 1})\end{array} \\
49.4\end{array}$} & \multirow{2}{*}{$\begin{array}{l}\text { Percentage of tested } \\
\text { children }(n=164)\end{array}$} \\
\hline Single parasite & Ascaris lumbricoides & & & \\
\hline mrections & Enterobius vermicularis & 3 & 3.7 & 1.8 \\
\hline & Strongyloides stercoralis & 2 & 2.5 & 1.2 \\
\hline & Hymenolepis nana & 17 & 21.0 & 10.4 \\
\hline & Hymenolepis diminuta & 1 & 1.2 & 0.6 \\
\hline & Taenia spp. & 4 & 4.9 & 2.4 \\
\hline & Dicrocoelium dendriticum & 1 & 1.2 & 0.6 \\
\hline & Giardia intestinalis & 31 & 38.3 & 18.9 \\
\hline & Entamoeba histolytica/dispar & 2 & 2.5 & 1.2 \\
\hline & lodamoeba bütschlii & 6 & 7.4 & 3.7 \\
\hline & Entamoeba coli & 31 & 38.3 & 18.9 \\
\hline & Endolimax nana & 1 & 1.2 & 0.6 \\
\hline \multirow[t]{24}{*}{ Co-infections } & $A l, G i, E c$ & 3 & 3.7 & 1.8 \\
\hline & $A l, H n, G i, E c$ & 2 & 2.5 & 1.2 \\
\hline & $\mathrm{Al}, \mathrm{Hn}$ & 2 & 2.5 & 1.2 \\
\hline & $A l, E C$ & 2 & 2.5 & 1.2 \\
\hline & $A l, E v$ & 1 & 1.2 & 0.6 \\
\hline & $A l$, Ss & 1 & 1.2 & 0.6 \\
\hline & $\mathrm{Al}, \mathrm{Hd}$ & 1 & 1.2 & 0.6 \\
\hline & $\mathrm{Al}, \mathrm{Hn}, \mathrm{Gi}$ & 1 & 1.2 & 0.6 \\
\hline & $A l, T$ & 1 & 1.2 & 0.6 \\
\hline & $A l, T, G i, E c$ & 1 & 1.2 & 0.6 \\
\hline & $A l, D d, G i, E c$ & 1 & 1.2 & 0.6 \\
\hline & $A l, G i, I b, E c$ & 1 & 1.2 & 0.6 \\
\hline & $E v, G i, E c$ & 1 & 1.2 & 0.6 \\
\hline & $E v, G i$ & 1 & 1.2 & 0.6 \\
\hline & Ss, Ec & 1 & 1.2 & 0.6 \\
\hline & $H n, G i, E c$ & 3 & 3.7 & 1.8 \\
\hline & $\mathrm{Hn}, \mathrm{Gi}$ & 1 & 1.2 & 0.6 \\
\hline & $H n, I b, E c, E n$ & 1 & 1.2 & 0.6 \\
\hline & $H n, I b, E c$ & 1 & 1.2 & 0.6 \\
\hline & $H n, E c$ & 1 & 1.2 & 0.6 \\
\hline & $T, E c$ & 1 & 1.2 & 0.6 \\
\hline & $\mathrm{Gi}, \mathrm{Ec}$ & 6 & 7.4 & 3.7 \\
\hline & $\mathrm{Gi}, \mathrm{Ib}$ & 2 & 2.5 & 1.2 \\
\hline & $E h / d, E c$ & 1 & 1.2 & 0.6 \\
\hline
\end{tabular}

Al - Ascaris lumbricoides; Ev - Enterobius vermicularis; Ss - Strongyloides stercoralis; Hn - Hymenolepis nana; Hd - Hymenolepis diminuta; T - Taenia spp.;

Dd - Dicrocoelium dendriticum; Gi - Giardia intestinalis; E h/d - Entamoeba histolytica/dispar; Ib - lodamoeba bütschlii; Ec - Entamoeba coli; En - Endolimax nana 
Table 3. Parasitic infections in Afghan adults

\begin{tabular}{lllll}
\hline Parasite infections & $\begin{array}{l}\text { Number of } \\
\text { infections }\end{array}$ & $\begin{array}{l}\text { Percentage of } \\
\text { infections }(\mathbf{n}=\mathbf{9})\end{array}$ & $\begin{array}{l}\text { Percentage of tested } \\
\text { adults }(\mathbf{n}=\mathbf{3 7})\end{array}$ \\
\hline $\begin{array}{l}\text { Single parasite } \\
\text { infections }\end{array}$ & Ascaris lumbricoides & 3 & 33.3 & 8.2 \\
& Dicrocoelium dendriticum & 1 & 11.1 & 2.7 \\
& Giardia intestinalis & 5 & 55.6 & 13.5 \\
& lodamoeba bütschlii & 2 & 22.2 & 5.4 \\
& Entamoeba coli & 3 & 33.3 & 8.2 \\
Co-infections & Al, Ib, EC & 1 & 11.1 & 2.7 \\
& Dd, Ib, Ec & 1 & 11.1 & 2.7 \\
& Gi, Ec & 1 & 11.1 & 2.7
\end{tabular}

Al-Ascaris lumbricoides; Dd - Dicrocoelium dendriticum; Gi - Giardia intestinalis; Ib - lodamoeba bütschlii; Ec - Entamoeba coli

rate (1/8 Afghan women die because of complications in pregnancy or labour), second in infant mortality rate (151 deaths per 1000 pregnancies) and third in the death rate of the whole population (17.65/1000 habitants die every year). One in 5 Afghan children dies before their fifth birthday [7]. The health service in Afghanistan is still based on non-governmental organisations' aid. A lack of health service workers (at every level) leads to problems with epidemiological control and consequently an increase in the number of infected people. In relation to the occurrence of contagious and parasitic diseases, Afghanistan is regarded as a high risk country. This is due to contaminated water and soil, limited access to the health service, a lack of basic drugs and medical equipment, large number of asymptomatic carriers of infective and parasitic diseases among local population as well as mass migration [8, 9]. The contamination of water with the pathogenic agents is common and only $31 \%$ of Afghan households have access to clean drinking water. Moreover, only $5-7 \%$ of the Afghan community has an access to basic standard toilets [10]. Chronic malnutrition is observed in over $50 \%$ of Afghan population [11]. Because of limited diagnostic and therapeutic capabilities of health services, Afghans are often treated by a trial and error method using a very poor assortment of pharmaceuticals. Reports concerning population morbidity rate are not confirmed by laboratory tests. Moreover, the low awareness of hygiene and disease prevention in Afghan community does not favour the situation. In Afghanistan, orally transmitted diseases are common as a consequence of poor hygienic standards of life and widespread contamination of water and food with both human and animal faeces. It is estimated that infections caused by intestinal parasites are extremely numerous. Amoebosis morbidity is $3 \%$ in the Afghan community and giardiasis morbidity may reach $11 \%$ in the child population. Possibly even $90 \%$ of Afghan citizens may be infected with more than one parasite [12]. However, this data was gathered by non-governmental organisations almost a decade ago and is only approximate and not confirmed by population screening studies. Therefore, they may not reflect the current epidemiological situation. Afghanistan is one of a few countries associated with the Organisation of the Islamic Cooperation (consisting of 57 countries), with no data about intestinal parasitic infections occurrence in this community [13]. In literature, there is little information concerning infections caused by intestinal parasites in Afghan refugees in the USA and Europe. In the $80 \mathrm{~s}$, an examination of 51 Afghans performed in USA showed that $32 \%$ of them were infected with Ascaris Iumbricoides, Giardia intestinalis, Entamoeba histolytica, Hymenolepis nana and Trichuris trichiura [14]. According to studies performed on 5928 of Afghan refugees between 1997 and 2003 in Sweden, 225 were infected with Giardia intestinalis [15]. One of a few parasitological researches in Afghanistan was performed in 2002 by the German Armed Forces health service stationed in Kabul. Among 217 local workers from the international military base (kitchen aids, translators, housekeeping personnel), 64\% were infected with intestinal helminths and protozoa, with Ascaris lumbricoides predominance observed (22.1\%) [16]. In 2003, World Health Organisation workers performed screening examination of stool samples taken from 1001 children aged 8-15 years in 4 provinces of the country. Results showed the occurrence of intestinal helminthiasis in $47 \%$ of children with the predominance of Ascaris lumbricoides (41\%) [17]. Results of the study presented in this paper, performed by the Polish health service in the local Afghan community, focused on the estimation of the prevalence of intestinal parasites in children and adults treated in Ghazni Provincial Hospital, in eastern Afghanistan.

\section{CONCLUSIONS}

The Afghan community, living in poor sanitary conditions with limited access to the health services, is one of the most infected populations in the world. The 
parasitological investigation focused on the detection of intestinal parasites performed by Polish health service in Afghanistan is still one of the few screening studies of this type.

\section{REFERENCES}

1. Kucik CJ, Martin GL, Sortor BV. Common intestinal parasites. Am Fam Physician 2004; 69: 1161-1168.

2. Hotez PJ, Molyneux DH, Fenwick A et al. Control of neglected tropical diseases. N Engl J Med 2007; 357: 1018-1027.

3. Harp JA. Parasitic infections of the gastrointestinal tract. Curr Opin Gastroenterol 2003; 19: 31-36.

4. Fernandez MC, Verghese S, Bhuvaneswari R et al. A comparative study of the intestinal parasites prevalent among children living in rural and urban settings in and around Chennai. J Commun Dis 2002; 34: 35-39.

5. Procedures for the Recovery and Identification of Parasites from the Intestinal Tract, Approved Guideline, M28-2A. Clinical and Laboratory Standards Institute, Villanova PA, 2005.

6. Garcia LS, Smith JW, Fritsche TR. Selection and use of laboratory procedures for diagnosis of parasitic infections of the gastrointestinal tract. ASM Press, Washington, DC 2003.

7. Central Intelligence Agency. World Factbook 2010. Available at: www.cia.gov/library/publications/the-world-factbook/geos/af.html. Accessed: 25.02.2011.
8. Wallace M, Hale BR, Utz GC et al. Endemic infectious diseases of Afghanistan. Clin Infect Dis 2002; 34: 171-207.

9. Korzeniewski K. Health hazards in Central Asia on Afghanistan example. IJHS 2009; 2: 154-157.

10. United Nations Environment Programme. Afghanistan's Environment 2008. National Environmental Protection Agency of the Islamic Republic of Afghanistan, Kabul 2009.

11. World Health Organization. Country Cooperation Strategy 2005 to 2009. Islamic Republic of Afghanistan, 03 August 2005.

12. Deployment Health Medical Center. Operation Enduring Freedom. USA 2005. Available at: http://www.pdhealth.mil/deployments/ enduring-freedom/concerns.asp.

13. Hotez PJ. The Neglected Tropical Diseases and Their Devastating Health and Economic Impact on the Member Nations of the Organisation of the Islamic Conference. PLoS Negl Trop Dis 2009; 3: e539.

14. McCaw BR, DeLay P. Demographics and disease prevalence of two new refugee groups in San Francisco. The Ethiopian and Afghan Refugees. West J Med 1985; 143: 271-275.

15. Ekdahl K, Andersson Y. Imported giardiasis: impact of international travel, immigration, and adoption. Am J Trop Med Hyg 2005; 72: 825-830.

16. Scheid PL, Thoma BR. Intestinal parasites in Afghan residents employed in Camp Warehouse, Kabul. Int J Med Microbiol 2004; 293 (suppl. 38): 62.

17. Gabrielli AF, Ramsan M, Naumann C et al. Soil-transmitted helminths and haemoglobin status among Afghan children in World Food Programme assisted schools. J Helminthol 2005; 79: 381-384. 